\title{
Spinal neuroschistosomiasis caused by Schistoma mansoni: cases reported in two brothers
}

\author{
Ana Lúcia Coutinho Domingues ${ }^{1}$, Constança Simões Barbosa ${ }^{2}$, Thiago Frederico Andrade $\mathrm{Agt}^{3}$, \\ Andréia Braga Mota ${ }^{3}$, Clélia Maria Ribeiro Franco ${ }^{3}$, Edmundo Pessoa Lopes ${ }^{1}$, Rodrigo Loyo $^{2}$ and \\ Elainne Christine Souza Gomes ${ }^{2^{*}}$
}

\begin{abstract}
Background: Spinal neuroschistosomiasis (SN) is one of the most severe clinical presentations of schistosomiasis infection and an ectopic form of the disease caused by any species of Schistosoma. In Brazil, all cases of this clinical manifestation are related to Schistosoma mansoni, the only species present in the country. Although many cases have been reported in various endemic areas in Brazil, this is the first time in the literature that SN is described in two brothers.

Case presentation: Two cases of SN were accidentally diagnosed during an epidemiological survey in an urban area endemic for schistosomiasis transmission. Both patients complained of low back pain and muscle weakness in the lower limbs. Sphincter dysfunction and various degrees of paresthesia were also reported. The patients' disease was classified as hepato-intestinal stage schistosomiasis mansoni at the onset of the chronic form. A positive parasitological stool test for S. mansoni, clinical evidence of myeloradicular damage and exclusion of other causes of damage were the basic criteria for diagnosis. After treatment with praziquantel and corticosteroid, the patients presented an improvement in symptoms, although some complaints persisted.

Conclusions: It is important to consider SN when patients come from areas endemic for transmission of schistosomiasis mansoni. Clinical physicians and neurologists should consider this diagnostic hypothesis, because recovery from neurological injuries is directly related to early treatment. As, described here in two brothers, a genetic predisposition may be related to neurological involvement. Primary care physicians should thus try to evaluate family members and close relatives in order to arrive at prompt schistosomiasis diagnosis in asymptomatic individuals and propose treatment in an attempt to avoid progression to SN.
\end{abstract}

Keywords: Spinal neuroschistosomiasis, Schistosomal myeloradiculopathy, Schistosoma mansoni, Case report, Diagnosis

\footnotetext{
*Correspondence: elainne.gomes@cpqam.fiocruz.br

${ }^{2}$ Department of Parasitology, Schistosomiasis Reference Laboratory, Aggeu Magalhães Institute, Fiocruz - Ministry of Health, Recife, PE 50740-465, Brazil

Full list of author information is available at the end of the article
}

(C) The Author(s). 2020 Open Access This article is licensed under a Creative Commons Attribution 4.0 International License, which permits use, sharing, adaptation, distribution and reproduction in any medium or format, as long as you give appropriate credit to the original author(s) and the source, provide a link to the Creative Commons licence, and indicate if changes were made. The images or other third party material in this article are included in the article's Creative Commons licence, unless indicated otherwise in a credit line to the material. If material is not included in the article's Creative Commons licence and your intended use is not permitted by statutory regulation or exceeds the permitted use, you will need to obtain permission directly from the copyright holder. To view a copy of this licence, visit http://creativecommons.org/licenses/by/4.0/ The Creative Commons Public Domain Dedication waiver (http://creativecommons.org/publicdomain/zero/1.0/) applies to the data made available in this article, unless otherwise stated in a credit line to the data. 


\section{Background}

Schistosomiasis is the parasitic disease that causes the second highest number of deaths around the world, second only to malaria [1]. The same epidemiological pattern is present in Brazil - with schistosomiasis being the parasitosis that causes the greatest number of deaths, after malaria. In Brazil, however, all cases are caused by Schistosoma mansoni--the only species of this parasite present in the country. The most recent national parasitological survey estimated that 1.5 million people are infected [2]. Despite the success of the Schistosomiasis Control Program, the severe (hepatosplenic) form of the disease and high mortality continue to pose a major public health problem [3]. Although rare in comparison to the hepatosplenic and intestinal forms of schistosomiasis, another serious manifestation is the ectopic form known as neuroschistosomiasis, which can affect any part of the central nervous system - CNS (brain and spinal cord). Neuroschistosomiasis is the second most common form of presentation of $S$. mansoni infection, beside the hepatosplenic form, although the asymptomatic form of neuroschistosomiasis is far more common than the symptomatic ones. Schistosomal myelopathy-the spinal form of schistosomiasis--tends to occur shortly after infection and is more likely to be symptomatic than cerebral schistosomiasis [4]. Clinical spinal neuroschistosomiasis (SN) syndrome is usually an acute or subacute myelopathy and may or may not be accompanied by polyradiculitis [5]. When $S$. mansoni is involved in the infection, SN with myeloradiculopathy is the most common neurological manifestation $[6,7]$.

In Brazil, $\mathrm{SN}$ is the third most common cause of myelopathy, after trauma and tumors [8]. Incidence of $\mathrm{SN}$ is not easy to measure, in view, especially, of the wide range of possible clinical manifestations [9]. However, since 1930, numerous cases of SN have been reported in the literature in Brazil, most of them "case reports" aiming to update the medical and research community regarding the occurrence, clinical presentation, severity and outcome of cases [6, 7, 10-13]. Epidemiologically, one of the most important studies was conducted in the three schistosomiasis mansoni referral hospitals in the Brazilian State of Pernambuco. In 2010, a data survey was carried out in Recife/Pernambuco using medical records covering 15 years of treatment of cases of schistosomiasis. The study gathered cases from departments of neurology and pediatrics, identifying 139 cases of SN in patients aged $2-83$ years. This study provided a large quantity of clinical-epidemiological information on $\mathrm{SN}$, including the distribution of the tendon reflex response (Achilles and patellar reflex absent or diminished in 79\% of patients), the incidence of spinal cord lesions $(40.3 \%$ in low thoracic, $15.8 \%$ in lumbar; and lowest incidence in lumbar-sacral - 0.7\%) and the results of complementary tests: absence of schistosoma eggs in $52 \%$ of stool parasitological exams; immunological tests using cerebrospinal fluid (CSF), 70\% positive by indirect immunofluorescence and $49.2 \%$ by ELISA; Magnetic resonance imaging (MRI) abnormal in 93\% of the cases; presence of schistosomal granulomas in rectal biopsy in $55.5 \%$ of cases [11].

It is known that the pathophysiology of clinical manifestations of SN involves the presence of S. mansoni eggs in the spinal cord causing an inflammatory response in the host, which subsequently results in the formation of a schistosomal granuloma [14, 15], as occurs in other tissues. It is also known that eggs reach the CNS mainly by way of retrograde venous flow through Batson's venous plexus. The eggs cause a granulomatous reaction strictly proportional to the number of eggs that reach the CNS. This reaction is also associated with the symptoms presented by patients, which include back pain, lower-limb muscle weakness, paresthesia, hypoesthesia, anesthesia, sphincter dysfunction (bladder and intestine), and others [7]. Apart from the wide range of non-specific symptoms, diagnosis of $\mathrm{SN}$ is not easy to perform, as there is no single test for the disease. Diagnosis is, therefore, presumptive and based on clinical features and test results, including dysfunctions and/or lesions of thoracic or lumbosacral spinal cord (clinical and image diagnosis), biochemical and immunological analysis of CSF, epidemiological and parasitological confirmation of S. mansoni infection, and exclusion of other causes of transverse myelitis $[6,7,11]$. Here we report for the first time in the literature the simultaneous occurrence of $\mathrm{SN}$ in two brothers.

\section{Case presentation}

Both cases were identified during a parasitological census survey carried out in Porto de Galinhas, Ipojuca, in the Brazilian State of Pernambuco, between July and December 2019. This location is internationally known not only for its beautiful beaches, but also for having become a new endemic area for schistosomiasis over the past 20 years $[15,16]$. This tourist zone is characterized as an urban transmission zone for schistosomiasis, in which foci for transmission of the disease concentrate around artificial breeding sites for vector snails (open sewage ditches) and people are infected in the rainy season when walking in the streets [16, 17]. Most of the 174 confirmed cases of schistosomiasis identified by an actual parasitological survey were residents of the poorest area in the locality, which lacks sanitary infrastructure, as were the two patients in the cases reported here. It is important to note that the vector in this location is the snail of greatest epidemiological importance in Brazil, Biomphalaria glabrata. 
In both cases, suspicion of $\mathrm{SN}$ arose during medical evaluation (November 2019), which included anamnesis and ultrasound. Patients complained of low back pain and difficulty walking. Both were referred to the neurology department of the clinical hospital of the Federal University of Pernambuco for investigation. During hospitalization, tests were performed to investigate other causes of myeloradicular involvement. Both patients presented serum testing negative for the HIV and HTLV retroviruses, negative for syphilis (VDRL), negative for rheumatological problems (antibodies for lupus, Sjogren, APS) and normal for vitamin B12 and copper. The patients also presented normal liver and spleen volume and surface, and absence of ascites in the abdomen ultrasound exam.

Detailed descriptions of each case and its evolution are presented below.

\section{Case 1}

A 36-year-old male artisan, child of non-consanguineous parents, began, in June 2019 (5 months before diagnosis), to experience paresthesia and ascending numbness in the right lower limb, associated with decreased strength in the same limb. The symptoms worsened over the course of several days and the patient reported that, after 2 weeks, the symptoms had spread to the left lower limb with similar characteristics. The patient also stated that, 2 weeks after the onset of the condition, he had experienced difficulty initiating urination, fecal retention and erectile dysfunction. His gait progressively worsened to the point where he was unable to walk without assistance. The patient also reported an intermittent sensation of fever, increased abdominal volume and weight loss of $5 \mathrm{~kg}$. He did not report any strenuous abdominal contraction (Valsalva maneuver) prior to his current complaints. His prior medical history did not reveal any other clinical comorbidities.

A parasitological stool examination using the KatoKatz method was positive for S. mansoni, with 36 eggs per gram of feces (EPG), characterizing a light parasitic load [18]. Ultrasound of the upper abdomen classified the clinical form of the disease as hepato-intestinal, with evidence of DC-pattern periportal fibrosis [19]. Neurological examination revealed the patient to be alert and oriented, but with asymmetric spastic crural paraparesis, predominantly proximal motor deficit, worse on the right, grade 3 muscle power in the left leg and grade 3 minus in the right leg. The patient had normal-active deep reflexes in the upper limbs, higher in the lower limbs, with bilateral cutaneous plantar extensor reflex (Babinski sign) and Achilles clonus. He had wellpreserved trophism and tactile hypoesthesia for superficial pain with asymmetric levels of sensation on the right at the sixth dorsal segment (T6) and on the left at the tenth dorsal segment (T10), associated with spastic gait.

The complete blood count (CBS) showed $4650 / \mathrm{mm}^{3}$ leukocytes, with $24 \%$ eosinophils. MRI of the spinal cord showed hyperintensity on a T2 sequence along the anterior segment of the thoracic and lumbar spinal cord, without contrast enhancement (Fig. 1). Lumbar cerebrospinal fluid collection showed a normal number of cells and biochemistry, normal values for the ADA test, and a negative VDRL test for syphilis. An aliquot of the CSF was reserved for DNA extraction and investigation of the presence of parasite DNA in the material, using the Loop-mediated isothermal amplification (LAMP) technique, as outlined in a previous publication [20], but insufficient material was collected to be able to perform the examination.

In view of clinical, laboratory and imaging evidence of neuroschistosomiasis, treatment was carried out as recommended by the Brazilian Ministry of Health. This involved high-dose corticosteroid therapy - methylprednisolone $1.0 \mathrm{~g} \mathrm{IV} /$ day for five consecutive days, a single dose of oral antiparasitic (praziquantel $50 \mathrm{mg} / \mathrm{kg}$ ), followed by oral corticosteroid therapy (prednisone 1 $\mathrm{mg} / \mathrm{kg} /$ day) over 6 months [21]. After 15 days, the patient had improved strength - measured on an international scale (modified medical research council) [22, 23] - from grade 3 to 4 in the left leg and from grade 3 minus to 4 in the right leg. This represented a significant improvement in sensitivity, although sphincter complaints and spasticity persisted. Use of oral corticosteroid therapy was continued for 6 months and muscle relaxants were prescribed for spasticity.

\section{Case 2}

A 37-year-old male patient, a general services assistant, child of the same parents as Case 1, began to experience low back pain radiating to the posterior thigh, similar to the sensation of being burnt or pricked by needles. This was followed by a decrease in tactile-pain sensation in the same region for more than 4 months prior to diagnosis. He did not report any abdominal contraction effort (Valsalva maneuver) prior to his current complaints. Two weeks after the onset of symptoms, the patient developed symmetrical weakness in the lower limbs and difficulty getting up from a sitting position. He also complained of sphincter problems, such as sporadic urinary incontinence around twice a week. These symptoms had progressed over the previous 2 months, mainly with pain in the right leg. No other clinical comorbidities appeared in the patient's medical history.

The Kato-Katz parasitological stool examination was positive for S. mansoni and identified 144 EPG, characterizing a moderate parasitic burden [18]. Ultrasound of the upper abdomen classified the clinical form of the 


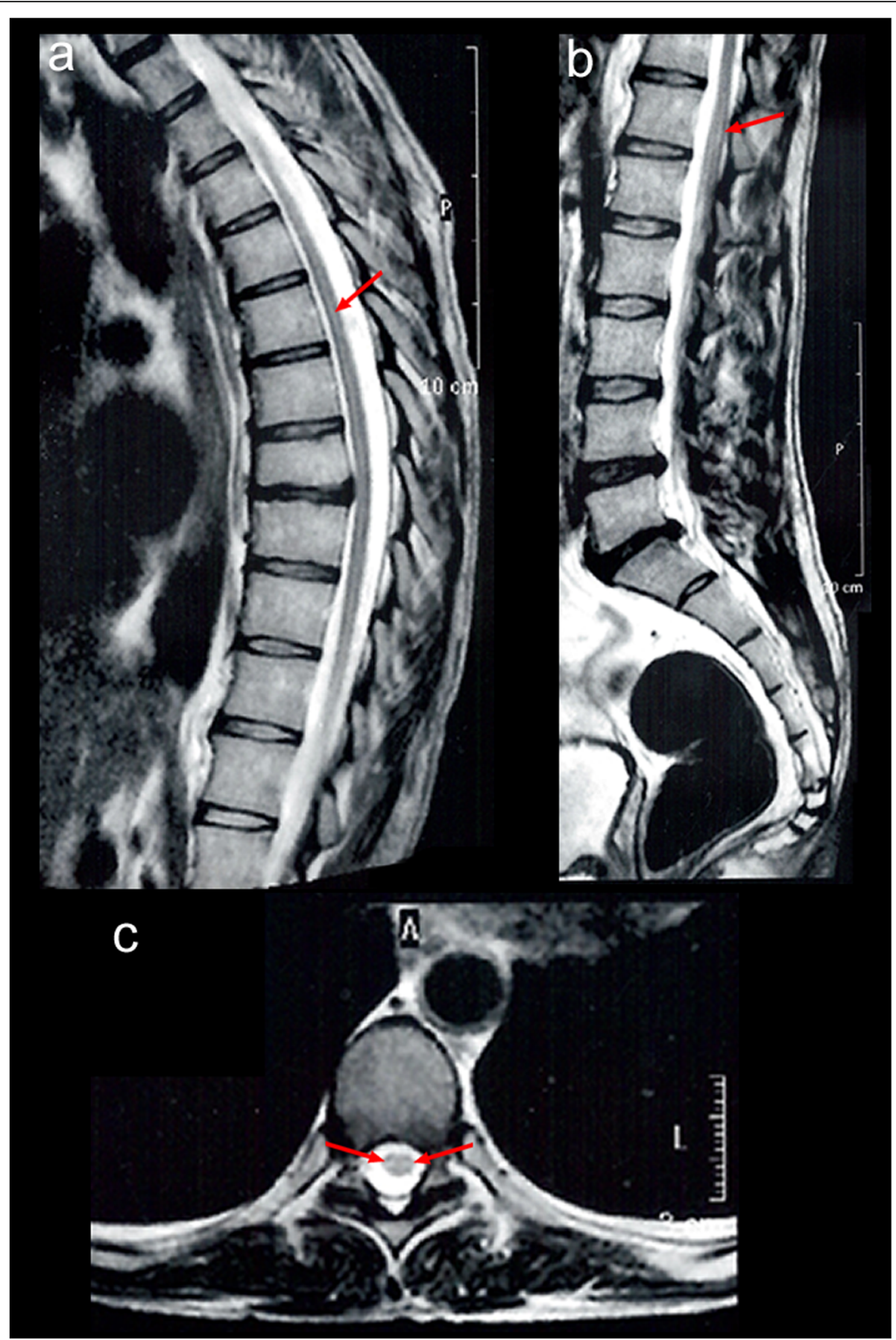

Fig. $1 \mathrm{MRl}$ of the thoracic and lumbosacral column of patient 1. a/b) T2 sagittal sections hyperintensity in thoracic and lumbosacral cord without gadolinium contrast enhancement. c) T2 axial sections hyperintensity in thoracic and lumbosacral cord without gadolinium contrast enhancement

disease as hepato-intestinal, with evidence of C-pattern periportal liver fibrosis [19]. Neurological examination showed the patient to be alert and oriented, but with predominantly proximal asymmetric spastic crural paraparesis (grade 3 in the left leg and grade 4 in the right leg), worse on the left. The patient had well-preserved trophism and presented bilateral pain-tactile hypoesthesia in the lumbosacral roots (L4-L5 and L5-S1) and pareto-spastic gait, worse in the left leg.

The CBC showed a total of $7400 / \mathrm{mm}^{3}$ leukocytes, with $8 \%$ eosinophils. MRI of the spinal cord showed hyperintensity in a T2 sequence along the anterior 
segment of the lumbar spinal cord (Fig. 2 a/b), with thickening of the lumbosacral spinal roots, using gadolinium contrast to study the T1 sequence (Fig. 2 c/d). Thoracic segment showed no abnormalities. Lumbar cerebrospinal fluid collection revealed normal cell numbers and biochemistry and normal values for the ADA test. The VDRL test was negative for syphilis. An aliquot of the CSF was reserved for DNA extraction and investigation of the presence of parasite DNA in the material, using the loop-mediated isothermal amplification (LAMP) technique. The test was positive for the presence of $S$. mansoni DNA in CSF.

This patient received the same oral corticosteroid and antiparasitic therapy as Case 1 . After 15 days, the patient had improved strength - measured on an international scale (modified medical research council) [22, 23]-from grade 3 to 4 in the left leg and grade 4 to 5 in the right leg, with no sphincter issues. Bilateral pain-tactile hypoesthesia in the lumbosacral roots, however, persisted in this patient (L4-L5 and L5-S1). Oral corticosteroid therapy was continued for 6 months, along with muscle relaxants to treat spasticity. Pregabalin has been used as a first line agent for the treatment of central neuropathic pain and was thus used to treat neuropathic pain in this patient [24].

Both patients will continue to be followed up in the neurology and gastroenterology department until such a time as the clinical sequelae improve.

\section{Discussion and conclusions}

Although SN can affect both men and women in the same way, both cases presented here occurred in young adult males. These results corroborate a number of studies reporting SN in children and young adults, most of them male $[10,11,25]$. These findings can be partially explained by the fact that males and young people experience greater exposure to situations associated with schistosomiasis infection, such as entering fresh water

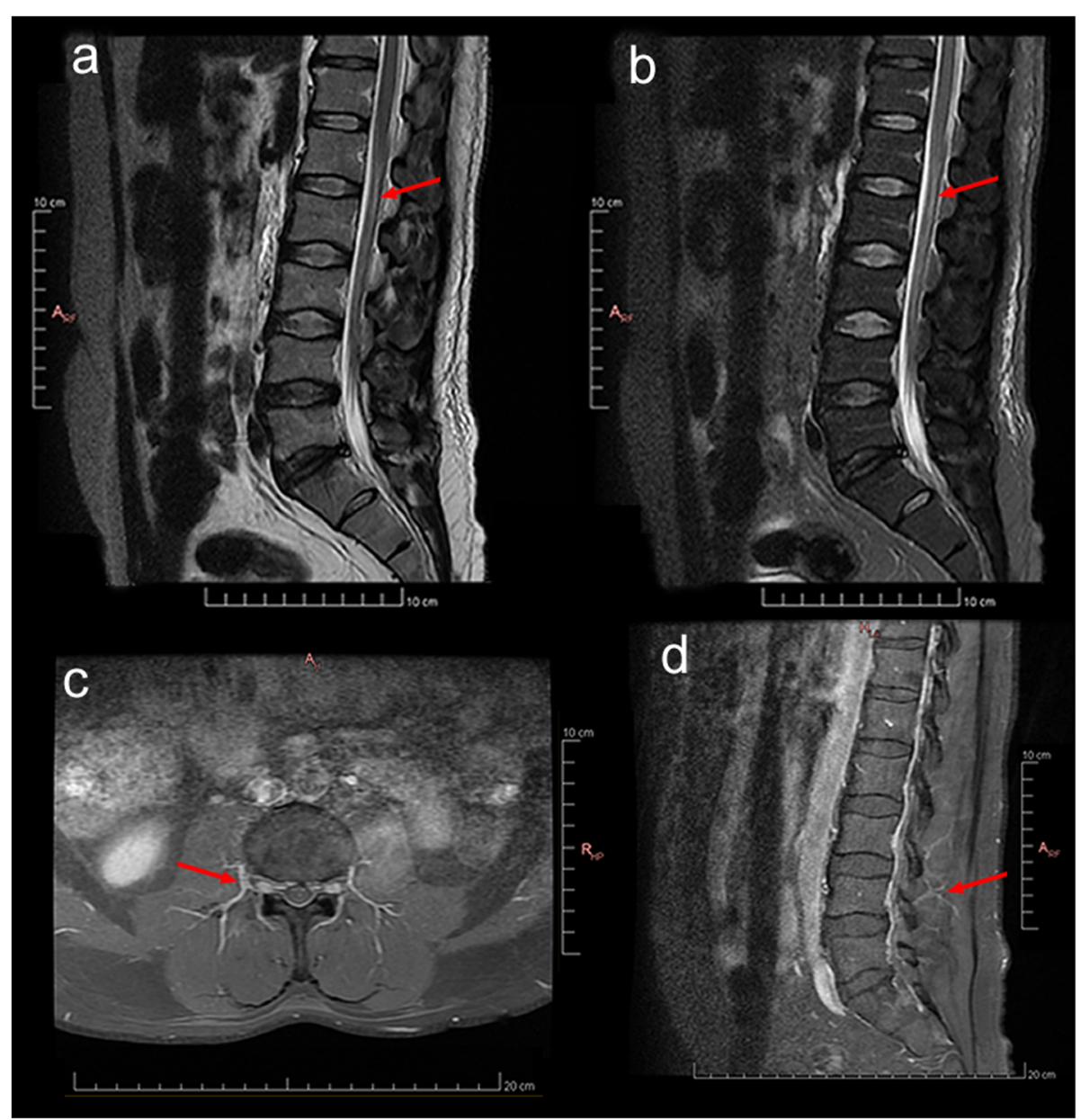

Fig. 2 MRI of the lumbosacral column of patient 2. a Sagittal T2 with root hypersignal at the cauda equina level. b Sagittal T2 with fat suppression with hypersignal at the cauda equina level. c Axial T1 with gadolinium contrast with root thickening at the L4 vertebral level and slight gadolinium contrast enhancement. $\mathbf{d}$ Sagittal T1 section with root thickening at the L4 vertebral level and slight gadolinium contrast enhancement 
containing snail vectors. In the particular case of urban transmission, young males are most likely to move through these localities during times of flooding, which are the periods when the disease is most highly transmissible [26]. It is important to note that the two cases described here share the same behavior related to risk of Schistosoma infection. Both brothers live in the neighborhood in the region that is most at risk for schistosomiasis infection, since it is the poorest in the locality and contains the largest number of breeding sites for Biomphalaria glabrata (14/36) and foci of transmission of the disease-- breeding sites with snails releasing cercaria $(7 / 9)$.

Although physical effort involving heightened abdominal pressure has been associated with the occurrence of $\mathrm{SN}$, none of the patients reported heavy work that could facilitate the passage of eggs through the Batson plexus $[7,13]$. However, the fact that these two brothers both developed SN may indicate that they present anastomosis of the veins of the portal-mesenteric and cerebrospinal system [27-29]. Another important finding that may help to explain the occurrence of $\mathrm{SN}$ in these two brothers is that, of the 174 cases identified with KatoKatz positive among the 2193 individuals who participated in the parasitological survey in the locality covered, these two cases were the only ones that presented SN. In view of these data, it is worth considering the possibility of some as yet unidentified genetic predisposition being responsible for the development of the neurological form in both brothers with schistosomiasis mansoni.

This is the first report of SN in siblings but, in France, similar cases have been reported in two brothers returning from a vacation in Madagascar. Both brothers had a history of bathing in stagnant freshwater until intense generalized pruritus forced them to leave the water. Schistosomiasis infection was confirmed by a stool examination testing positive for S. mansoni and cerebral neuroschistosomiasis was also confirmed [30]. Both cases reported here were in the initial chronic stage of the disease, diagnosed by ultrasound and blood count as the hepato-intestinal form of schistosomiasis, indicating that patients could have been infected in the previous few months and were in the phase of established active infection, with inflammatory response against parasite eggs $[19,31]$. The immunological response has been implicated in the clinical manifestation of SN. Some studies have indicated that CNS lesions and SN symptoms are more accentuated among recently infected individuals $[25,30]$, when the patient is evolving from the acute to the chronic phase, presenting the hepato-intestinal form of the disease [7], as occurred in the two cases reported here. It is important to note that Patient 1 had more symptoms and greater neurological impairment, even though he presented the lower parasite load and greater damage to the liver (fibrosis), compatible with a stronger immune response.

All the symptoms presented in these cases have been extensively described in the literature and are expected manifestations of SN. Low back pain, lower-limb muscle weakness, some kind of lower-limb paresthesia (symmetric or asymmetric) and gait disorder have been described in most cases of $\mathrm{SN}[6,7,10,11,14,15,32]$. A prospective study of $63 \mathrm{SN}$ patients found bladder, intestinal and sexual dysfunction in 98.6, 87.0 and $91.4 \%$, respectively $[7,32]$, in keeping with the symptoms presented by the patients studied here. A diagnosis of neuroschistosomiasis should be considered whenever a patient with a history of exposure to schistosome-infected water presents either seizure, ataxia, increased intracranial pressure, hemianopsia, nystagmus and vertigo or paraplegia, sphincter dysfunction, or sensory disturbances from the pelvic girdle down, as these are the neurological alterations usually produced by cerebral or spinal cord SN [13].

MRIs of the spinal cord have shown enhancement of the medullar signal. A fine, diffuse, nodular heterogeneous pattern of contrast enhancement after gadolinium administration has been described. Both of these are changes compatible with inflammation and/or demyelination in the thoraco-lumbar segment and lumbosacral roots. The lower thoracic to lumbosacral segments of the spine represent the main area damaged by $S$. mansoni eggs in cases of $\mathrm{SN}[7,11]$. MRI is considered more sensitive than computer tomography but both methods may show evidence of spinal cord atrophy in the later phase of the disease [13,33].

Other complementary tests, such as serology for other infectious diseases associated with symptoms of myelitis, were performed to rule out other causes of this manifestation, as recommended by the Centers for Disease Control and Prevention [34]. CSF very reliably reflects the inflammatory process that damages the spinal cord, which includes lymphomononuclear hypercellularity associated with the presence of eosinophils, an increase in the concentration of proteins, and the presence of antibodies for $S$. mansoni, although it is possible to find cases with a normal CSF profile $[4,13]$. The use of LAMP is an especially promising auxiliary method for diagnosis of $\mathrm{SN}$, as it is an extremely sensitive and specific method for detecting the presence of $S$. mansoni DNA in biological samples [31]. LAMP has been proved to be efficient by one parasitological survey, presenting sensitivity of $92.86 \%$ and specificity of $80.11 \%$ in stool samples [20], which are much more difficult to process. It is important to note that another type of molecular test similar to LAMP, real-time PCR, has already been used to diagnose SN in CSF samples [35]. 
After treatment, which followed the national (Brazilian Ministry of Health) and international recommendations by administrating corticosteroids to reduce the inflammatory process and clinical manifestations and treating schistosomiasis with praziquantel $[15,21]$, the two patients presented some improvement in symptoms. Case 1 , however, continued to experience urinary and fecal retention and spasticity of gait and Case 2 continued to exhibit sensitivity and worsening back pain. As reported in the literature, the outcome of $\mathrm{SN}$ is directly related to early diagnosis and treatment [7]. In the cases reported here, the patients were diagnosed 4 and 5 months after the onset of symptoms, in the early chronic phase of the disease and this may be directly related to their poor response to treatment. Both were therefore put on a sixmonth regimen of corticosteroid therapy and prescribed chronic pain medications, such as anticonvulsants and muscle relaxants. A second $S$. mansoni treatment may be necessary to ensure all worms were killed.

Finally, the publication of these cases of neuroschistosomiasis caused by S. mansoni, involving two brothers, should alert the primary care physicians to the need for early diagnosis of this form of presentation of infection in endemic areas. Furthermore, after diagnosis of a case, screening for other cases in the region should be undertaken, especially in family members and close relatives, since a genetic predisposition may be related to neurological involvement. Early diagnosis may thus help to ensure prompt treatment and improve the prognosis for neuroschistosomiasis.

\section{Abbreviations \\ ADA: Adenosine deaminase; APS: Antiphospholipid syndrome; \\ CBS: Complete blood count; CNS: Central nervous system; CSF: Cerebrospinal fluid; DNA: Deoxyribonucleic acid; EPG: Eggs per gram of feces; HIV: Human immunodeficiency virus; HTLV: Human T lymphotropic virus; IV: Intravenous; KG: Kilogram; LAMP: Loop-mediated isothermal amplification; MG: Milligram; MRI: Magnetic resonance imaging; S. mansoni: Schistosoma mansoni; SN: Spinal neuroschistosomiasis; VDRL: Venereal Disease Research Laboratory}

\section{Acknowledgements}

We would like to express our gratitude to the patients who agreed to participate in this study.

\section{Authors' contributions \\ All authors have read and approved the manuscript. Each author has contributed individually and significantly to the development of the manuscript. ALCD was the physician who clinically evaluated the patients, performed ultrasonography and raised the diagnostic hypothesis of SN. CSB is the researcher responsible for the parasitological survey carried out in the locality. TFAVA, ABM and CMRF were the neurologists responsible for the neurological assessment of patients. EPL was the physician responsible for monitoring patients during hospitalization. RL was responsible for performing the parasitological and molecular tests (LAMP). ECSG is the researcher responsible for general coordination of the field and laboratory activities for this study and was the main contributors to drafting the manuscript.}

\section{Funding}

This study is supported by the National Council for Scientific and Technological Development (CNPq) and Aggeu Magalhães Institute, Oswaldo Cruz Foundation (IAM/ Fiocruz) (PROEP No.400715/2019-8). The role of the funding body is in the design of the study and collection, analysis, and interpretation of data and in writing the manuscript.

\section{Availability of data and materials}

All data and materials are available with the corresponding author.

\section{Ethics approval and consent to participate}

This manuscript if part of a major project that was approved by the Research Ethics Committee of the Aggeu Magalhães Institute - Fiocruz, under the number CAAE 02075118.0.0000.5190.

\section{Consent for publication}

Written informed consents were obtained from the patients for publication of these cases reported.

\section{Competing interests}

The authors declare that they have no competing interests.

\section{Author details}

${ }^{1}$ Department of Gastroenterology, Clinical Hospital, Federal University of Pernambuco, Av. Prof. Moraes Rego, 1235, Cidade Universitária, Recife, PE 50670-901, Brazil. Department of Parasitology, Schistosomiasis Reference Laboratory, Aggeu Magalhães Institute, Fiocruz - Ministry of Health, Recife, PE 50740-465, Brazil. ${ }^{3}$ Department of Neurology, Clinical Hospital, Federal University of Pernambuco, Av. Prof. Moraes Rego, 1235, Cidade Universitária, Recife, PE 50670-901, Brazil.

Received: 6 May 2020 Accepted: 16 September 2020

Published online: 02 October 2020

\section{References}

1. Steinmann P, Keiser J, Bos R, Tanner M, Utzinger J. Schistosomiasis and water resources development: systematic review, meta-analysis, and estimates of people at risk. Lancet Infect Dis. 2006;6:411-25. https://doi.org/ 10.1016/S1473-3099(06)70521-7.

2. Noya O, Katz N, Pointier JP, Theron A, Alarcón de Noya B. Schistosomiasis in America. In: Franco-Paredes C, Santos-Preciado JI, editors. Neglected Tropical Diseases - Latin America and the Caribbean. Vienna: Springer Vienna; 2015. p. 114-24. https://doi.org/10.1007/978-3-7091-1422-3.

3. Barbosa CS, Gomes EC de S, Campos JV, de Oliveira FJM, da Silva Mesquita MC, de Oliveira ECA, et al. Morbidity of mansoni schistosomiasis in Pernambuco-Brazil: analysis on the temporal evolution of deaths, hospital admissions and severe clinical forms (1999-2014). Acta Trop 2016;164:10-16.

4. Carod-Artal FJ, Vargas AP, Horan TA, Marinho PB, Coelho Costa PH. Schistosoma mansoni myelopathy: clinical and pathologic findings. Neurology. 2004;63:388-91.

5. Peregrino AJP, Puglia PMK, Nóbrega JPS, Livramento JA, Marques-Dias MJ, Scaff M. Esquistossomose medular: análise de 80 casos. Arq Neuropsiquiatr. 2002;60:603-8.

6. Ferrari TCA, Moreira PRR. Neuroschistosomiasis: clinical symptoms and pathogenesis. Lancet Neurol. 2011;10:853-64. https://doi.org/10.1016/S14744422(11)70170-3.

7. Ferrari TCA, Moreira PRR, Cunha AS. Clinical characterization of neuroschistosomiasis due to Schistosoma mansoni and its treatment. Acta Trop. 2008;108:89-97.

8. Brito JC de F, Nóbrega PV da. Mielopatias: Considerações clínicas e aspectos etiológicos. Arq Neuropsiquiatr. 2003:61 3 B:816-21.

9. Santos EC dos, Campos GB, Diniz AC, Leal JC, Rocha MO da C. Perfil clínico e critérios diagnósticos da mielorradiculopatia esquistossomótica. Arq Neuropsiquiatr. 2001;59 3 B:772-7.

10. Araújo KCGM, Silva C da RE, Barbosa CS, Ferrari TCA. Clinical-epidemiological profile of children with schistosomal myeloradiculopathy attended at the Instituto Materno-Infantil de Pernambuco. Mem Inst Oswaldo Cruz. 2006;101 SUPPL. 1:149-56.

11. Araújo KCGM de, Silva C da R e, Santos AGA dos, Barbosa CS, Ferrari TCA. Clinical-epidemiologic profile of the schistosomal myeloradiculopathy in Pernambuco, Brazil. Mem Inst Oswaldo Cruz 2010;105:454-459.

12. Lambertucci JR, Sousa-Pereira SR, Silva LC dos S. Myeloradiculopathy in acute schistosomiasis mansoni. Rev Soc Bras Med Trop 2005;38:277-278. 
13. Nascimento-Carvalho CM, Moreno-Carvalho OA. Neuroschistosomiasis due to Schistosoma mansoni: a review of pathogenesis, clinical syndromes and diagnostic approaches. Rev Inst Med Trop Sao Paulo. 2005;47:179-84.

14. Carod-Artal FJ. Neurological complications of Schistosoma infection. Trans R Soc Trop Med Hyg. 2008;102:107-16.

15. Ross AG, Mcmanus DP, Farrar J, Hunstman RJ, Gray DJ, Li Y-S. Neuroschistosomiasis. J Neurosci. 2012;259:22-32.

16. Barbosa CS, Lúcia A, Domingues C, Abath F, Maria S, Montenegro L, et al. Epidemia de esquistossomose aguda na praia de Porto de Galinhas, Pernambuco, Brasil,Cad Saúde Pública 2001;17:725-728. http://www.scielo. br/pdf/csp/v17n3/4656.pdf. Accessed 28 May 2017.

17. Gomes EC de S, Leal-Neto OB, Albuquerque J, Pereira da Silva H, Barbosa CS. Schistosomiasis transmission and environmental change: a spatiotemporal analysis in Porto de Galinhas, Pernambuco--Brazil. Int J Health Geogr 2012:11:51. doi:https://doi.org/10.1186/1476-072X-11-51.

18. WHO Expert committee. Prevention and Control of Schistosomiasis and Soil-Transmitted Helminthiasis. World Heal Organ. 2002;912:1-57.

19. Richter J, Domingues ALC, Barata CH, Prata AR, Lambertucci JR. Report of the Second Satellite Symposium on Ultrasound in Schistosomiasis. Mem Inst Oswaldo Cruz. 2001;96 SUPPL.:151-156.

20. Gandasegui J, Fernández-Soto P, Muro A, Barbosa CS, de Melo FL, Loyo R, et al. A field survey using LAMP assay for detection of Schistosoma mansoni in a low-transmission area of schistosomiasis in Umbuzeiro, Brazil: Assessment in human and snail samples. PLoS Negl Trop Dis. 2018;12. e0006314. https://doi.org/10.1371/journal.pntd.0006314.

21. Ministério da Saúde. Guia de vigilância epidemiológica e controle da mielorradiculopatia esquistossomótica. Secr Vigiláncia em Saúde. 2006,:32.

22. Medical Research Council. Aids to the examination of the peripheral nervous system. London Her Majesty's Station Off. 1943;45:62.

23. Dyck PJ, Boes CJ, Mulder D, Millikan C, Windebank AJ, Dyck PJB, et al. History of standard scoring, notation, and summation of neuromuscular signs. A current survey and recommendation. J Peripher Nerv Syst. 2005;10:158-73.

24. Attal N, Cruccu G, Baron R, Haanpää M, Hansson P, Jensen TS, et al. EFNS guidelines on the pharmacological treatment of neuropathic pain: 2010 revision. Eur J Neurol. 2010;17:1113-23.

25. Vidal CHF, Gurgel FV, Ferreira MLB, de Azevedo-Filho HRC. Epidemiological aspects in neuroschistosomiasis. Arq Neuropsiquiatr. 2010;68:72-5.

26. Gomes EC de S, Leal-Neto OB, Oliveira FJM, Campos JV, Souza-Santos R, Barbosa CS. Risk analysis for occurrences of schistosomiasis in the coastal area of Porto de Galinhas, Pernambuco, Brazil,BMC Infect Dis 2014;14:1-12. doi:https://doi.org/10.1186/1471-2334-14-101.

27. Rodesch G, Hurth M, Alvarez H, Tadié M, Lasjaunias P. Classification of spinal cord arteriovenous shunts: proposal for a reappraisal - the Bicêtre experience with 155 consecutive patientes treated between 1981 and 1999. Neurosurgery. 2002;51:374-80.

28. Rodesch G, Lasjaunias P. Spinal cord arteriovenous shunts: from imaging to management. Eur J Radiol. 2003;46:221-32.

29. Wendl CM, Aguilar Pérez M, Felber S, Stroszczynski C, Bäzner H, Henkes H. Paraspinal arteriovenous fistula: Stuttgart classification based on experience and a review of the literature. Br J Radiol. 2018:91:1-10.

30. Houdon L, Flodrops $H$, Rocaboy M, Bintner M, Fériot JP, Tournebize $P$, et al. Two patients with imported acute neuroschistosomiasis due to schistosoma mansoni. J Travel Med. 2010;17:274-7.

31. Mcmanus DP, Dunne DW, Sacko M, Utzinger J, Vennervald BJ, Zhou X-N. Schistosomiasis. Nat Rev Dis Prim. 2018:4:1-19.

32. Ferrari TCA, Moreira PRR, Cunha AS. Spinal cord schistosomiasis: a prospective study of 63 cases emphasizing clinical and therapeutic aspects. J Clin Neurosci. 2004;11:246-53.

33. Silva LC dos S, Maciel PE, Ribas JGR, Pereira SR de S, Serufo JC, Andrade LM, et al. Mielorradiculopatia esquistossomótica. Rev Soc Bras Med Trop 2004;37:261-272.

34. Center for Disease Control and Prevention. Acute Schistosomiasis with transverse myelitis in American students returning from Kenya. Morb Mortal Wkly Rep. 1984; 33:445-7 https://www.cdc.gov/mmwr/preview/mmwrhtml/00000385.htm.

35. Härter G, Frickmann H, Zenk S, Wichmann D, Ammann B, Kern P, et al Diagnosis of neuroschistosomiasis by antibody specificity index and semiquantitative real-time PCR from cerebrospinal fluid and serum. J Med Microbiol. 2014;63:309-12.

\section{Publisher's Note}

Springer Nature remains neutral with regard to jurisdictional claims in published maps and institutional affiliations.

Ready to submit your research? Choose BMC and benefit from:

- fast, convenient online submission

- thorough peer review by experienced researchers in your field

- rapid publication on acceptance

- support for research data, including large and complex data types

- gold Open Access which fosters wider collaboration and increased citations

- maximum visibility for your research: over $100 \mathrm{M}$ website views per year

At BMC, research is always in progress.

Learn more biomedcentral.com/submissions 